\title{
Excess Properties for the Binary System Diethylene Glycol Dibutyl Ether - Ethanol
}

\author{
MARIA MAGDALENA BUDEANU*, VASILE DUMITRESCU \\ Chemistry Department, Petroleum and Gas University of Ploiesti, Ploiesti, Romania
}

\begin{abstract}
This paper reports propertiesdata at 20, 25 and $30{ }^{\circ} \mathrm{C}$ and 1 atmosphere pressure for diethylene glycol dibutyl ether - ethanol system depending on concentration. The experimental values of density and viscosities of pure components and mixtures were correlated with temperature. The excess properties were determined from experimental data of densities and viscosities. These excess values were correlated to Hwang and Redlich-Kister equations. The value of excess molar volume for equimolar solution was compared with the values calculated from the Flory and Prigogine-FloryPatterson theories.
\end{abstract}

Keywords: binary mixtures, excess properties, diethylene glycol dibutyl ether, ethanol

\section{Introduction}

Density, viscosity and refractive index of solutions determined at different temperatures and compositions are some physical properties used for the design of industrial plants, pipelines and pumps. The values of these properties are used for design and optimization of the chemical processes [1].

The experimental values of some physical properties of pure substances and mixtures are necessary for the study of liquids under operating conditions. Thus, density is used to calculate other thermophysical properties and in engineering calculations [2].

Identifying the type of intermolecular interactions that occur between the compounds of the binary solutions requires the determination of excess properties such as molar volume, deviation in viscosity and excess Gibbs free energy [3].

The study of binary solutions of alcohols with polyethers presents a particular interest in describing interactions occurring between solutions components. Thus, the study of this type of solutions represents a challenge for any proposed model [4].

Glycol ethers are used in industry as solvents with great potential for gas sweetening [5]. These ethers are utilised as scrubbing liquids in the cleaning of exhaust air and gas streams from industrial production plants [6].

\section{Materials and methods}

The diethylene glycol dibutyl ether (DEGDBE) (purity > 0.99) and ethanol (purity > 0.98) were dried over molecular site (Fluka type $4 \AA$ ). The purity was verified by chromatographic analysis. The mole fractions were obtained by weighing and precision was \pm 0.0002 .

The densities were measured using a calibrated glass pycnometer and the estimated accuracy was $\pm 0.0004 \mathrm{gcm}^{-3}$. The details of the measurement techniques are given previously [7].

Ubbelohde kinematic viscometer was used for experimental viscosities measurements. The details procedure was described earlier [8].

The dynamic viscosity $\eta$ was calculated with the relation:

$$
\eta=v \rho
$$

where $\rho$ is the density and $v$ is the kinetic viscosity. The accuracy in dynamic viscosities determinations was $\pm 0.0005 \mathrm{mPas}$.

*email: maria.budeanu@upg-ploiesti.ro 


\section{Results and discussions}

In tables 1 and 2 are presented the results of the experimental densities and viscosities for the pure compounds and respectively for the binary solutions. The values of densities presented by us differ from those in the literature with $0.009 \%$ for DEGDBE and $0.1 \%$ for ethanol. In the case of viscosity, the differences are $0.9 \%$ for DEGDBE and $1 \%$ for ethanol.

Table 1. Densities and viscosities of the pure compounds

\begin{tabular}{|c|c|c|c|c|c|}
\hline \multirow[b]{2}{*}{ Component } & \multirow[t]{2}{*}{$t /{ }^{\circ} \mathrm{C}$} & \multicolumn{2}{|c|}{$\rho / \mathrm{g} \cdot \mathrm{cm}^{-3}$} & \multicolumn{2}{|c|}{$\eta / \mathrm{mPa} s$} \\
\hline & & Exp & Lit & Exp & Lit \\
\hline \multirow{4}{*}{ DEGDBE } & 20 & 0.8822 & - & 2.4090 & - \\
\hline & 25 & 0.8787 & $0.8785[9]$ & 2.1406 & $2.160[9]$ \\
\hline & & & $0.87862[10]$ & & $2.122[4]$ \\
\hline & 30 & 0.8731 & - & 1.7549 & - \\
\hline \multirow{3}{*}{ Ethanol } & 20 & 0.7896 & $0.789547[11]$ & 1.2184 & $1.2097[12]$ \\
\hline & 25 & 0.7857 & $0.7857[12]$ & 1.1087 & $1.0990[12]$ \\
\hline & 30 & 0.7817 & $0.780942[11]$ & 1.0077 & $0.9971[12]$ \\
\hline
\end{tabular}

Table 2. Densities and viscosities of the degdbe - ethanol solutions

\begin{tabular}{|c|c|c|c|c|c|c|}
\hline \multirow{2}{*}{$x$} & \multicolumn{3}{|c|}{$\rho / \mathrm{g} \cdot \mathrm{cm}^{-3}$} & \multicolumn{3}{c|}{$\eta / \mathrm{mPa} \cdot \mathrm{s}$} \\
\cline { 2 - 7 } & \multicolumn{3}{|c|}{$t /{ }^{0} \mathrm{C}$} & \multicolumn{3}{c|}{} \\
\cline { 2 - 7 } & 20 & 25 & 30 & 20 & 25 & 30 \\
\hline 0.1055 & 0.8222 & 0.8186 & 0,8144 & 1.2937 & 1.1717 & 1.0499 \\
0.2088 & 0.8413 & 0.8379 & 0,8333 & 1.3749 & 1.2418 & 1.0912 \\
0.3118 & 0.8534 & 0.8499 & 0,8451 & 1.4728 & 1.3222 & 1.1495 \\
0.4149 & 0.8618 & 0.8583 & 0,8533 & 1.5966 & 1.4288 & 1.2278 \\
0.5117 & 0.8675 & 0.8640 & 0,8589 & 1.7172 & 1.5348 & 1.3056 \\
0.6138 & 0.8722 & 0.8686 & 0,8634 & 1.8592 & 1.6576 & 1.3935 \\
0.7107 & 0.8756 & 0.8721 & 0,8668 & 1.9910 & 1.7794 & 1.4826 \\
0.8087 & 0.8785 & 0.8750 & 0,8696 & 2.1313 & 1.9007 & 1.5734 \\
0.9039 & 0.8806 & 0.8771 & 0,8717 & 2.2706 & 2.0212 & 1.6635 \\
\hline
\end{tabular}

Densities and viscosities of the pure components and binary mixtures were analyzed according to temperature with the equations 2 and respectively 3 [13]:

$$
\begin{gathered}
\rho=a_{0}+a_{1} T \\
\eta=\eta_{0} e^{\frac{E a}{R T}}
\end{gathered}
$$

where $a_{0}, a_{1}, \eta_{0}$ and $E_{\mathrm{a}}$ represent the estimated parameters.

These parameters were calculated using the Levenberg-Marquardt algorithm [14]. In table 3 are present the estimated parameters and standard deviation $(\sigma)$ computed with relation:

$$
\sigma=\left[\frac{\sum\left(Y_{\text {exp }}-Y_{\text {calc }}\right)^{2}}{m-n}\right]^{1 / 2}
$$

where $Y$ represents the value of the measured property, $m$ and $n$ represent the number of values and respectively the number of adjustable parameters.

Table 3. Parameters and standard deviation fordegdbe $(x)$ - ethanol

\begin{tabular}{|c|c|c|c|c|c|c|}
\hline$x$ & $a_{0}$ & $a_{1} \cdot 10^{4}$ & $\sigma \cdot 10^{4}\left(\mathrm{~g} / \mathrm{cm}^{3}\right)$ & $10^{4} \cdot \eta_{0}$ & $E_{a}(\mathrm{~kJ} / \mathrm{mol})$ & $\sigma \cdot 10^{2}(\mathrm{mPa} \cdot \mathrm{s})$ \\
\hline 0.0000 & 1.02 & -7.9 & 0.41 & 38.9 & 14.01 & 0.20 \\
0.1055 & 1.05 & -7.8 & 2.45 & 23.9 & 15.35 & 0.67 \\
0.2088 & 1.08 & -8.0 & 4.90 & 13.5 & 16.88 & 1.57 \\
0.3118 & 1.09 & -8.3 & 5.31 & 8.89 & 18.08 & 1.93 \\
0.4149 & 1.11 & -78.5 & 6.12 & 6.34 & 19.10 & 2.58 \\
0.5117 & 1.12 & -8.6 & 6.53 & 4.99 & 19.86 & 3.32 \\
0.6138 & 1.13 & -8.8 & 6.53 & 3.64 & 20.83 & 4.21 \\
0.7107 & 1.13 & -8.8 & 7.35 & 3.33 & 21.21 & 5.31 \\
0.8087 & 1.14 & -8.9 & 7.76 & 2.80 & 21.80 & 6.00 \\
0.9039 & 1.14 & -8.9 & 7.76 & 2.42 & 22.32 & 6.70 \\
1.0000 & 1.15 & -9.1 & 8.57 & 2.18 & 22.71 & 7.28 \\
\hline
\end{tabular}


The values of the standard deviation $(\sigma)$ show that the analyzed equations correlate well our experimental data.

\section{Excess properties}

The excess molar volumes were determined from the densities of the components and their solutions using the relation:

$$
V^{E}=\left[x M_{1}+(1-x) M_{2}\right] / \rho-\left[x M_{1} / \rho_{1}+(1-x) M_{2} / \rho_{2}\right]
$$

where $x$ and (1-x) represent the mole fraction of the compounds, $M_{1}$ and $M_{2}$ represent the molecular masses of the compounds 1 and 2 , and $\rho, \rho_{1}$ and $\rho_{2}$ represent the densities of the mixtures and of the pure compounds.

The excess viscosity $\left(\eta^{\mathrm{E}}\right)$ was calculated with the relation:

$$
\eta^{E}=\eta-\left(x \eta_{1}+(1-x) \eta_{2}\right)
$$

where $\eta_{1}$ and $\eta_{2}$ represent the viscosities of pure compounds.

The excess Gibbs energies $\left(\Delta G^{\mathrm{E}}\right)$ have been calculated with the relation:

$$
\Delta G^{E}=R T\left[\ln (\eta V)-x \ln \left(\eta_{1} V_{1}\right)-(1-x) \ln \left(\eta_{2} V_{2}\right)\right]
$$

Figure 1 shows $V^{\mathrm{E}}$ data for binary mixtures for the three temperatures studied. The excess molar volume presents negative values for all concentrations and they increase with increased temperature. The curves are not symmetric and have a maximum value for the solution with higher ethanol concentration. The negative $V^{\mathrm{E}}$ shows that there is a volume contraction on mixing [15]. The intermolecular self-association of the polyethers is relatively more feebler than that of alcohol. This can be explain by the possible presence of dipole-dipole association in polyethers, which has no important influence on the self-associated ethanol on mixing [4].

The excess viscosities are illustrated in figure 2. All values are negative at any composition an at all investigating temperatures. The negative values show the important factor of breaking of the selfassociated alcohols and feeble interactions between unlike molecules [16]. A decrease in the values of excess viscosity is observed with increasing temperature.

Figure 3 shows the positive values of excess Gibbs energy. The positive values of $\Delta G^{\mathrm{E}}$ are considered to be a useful indicator of the presence of specific interactions $[17,18]$ between components. It is noting that the excess Gibbs energy decreases with increasing temperature.

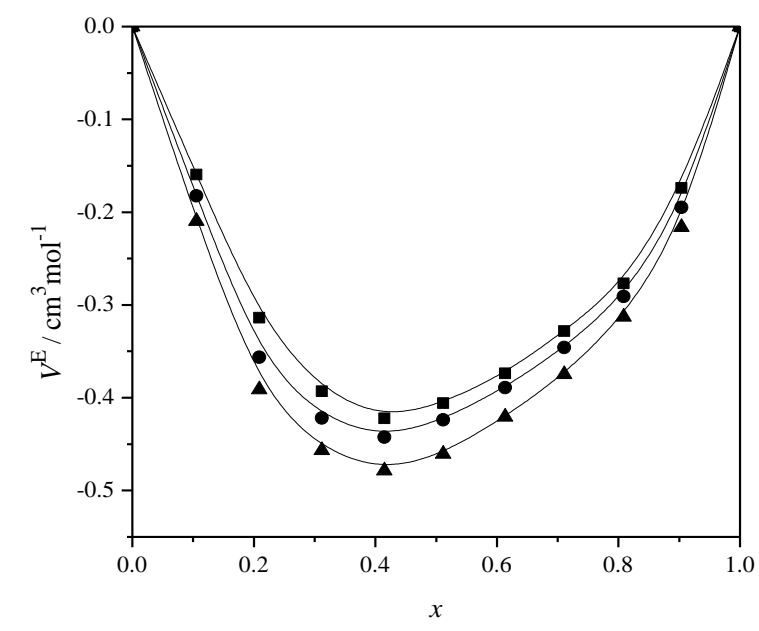

Figure 1. Excess molar volumes as a function of concentration for DEGDBE $(x)$ - ethanol $\bullet 20{ }^{\circ} \mathrm{C} ; \bullet 25{ }^{\circ} \mathrm{C} ; \boldsymbol{\Delta} 30{ }^{\circ} \mathrm{C}$. 


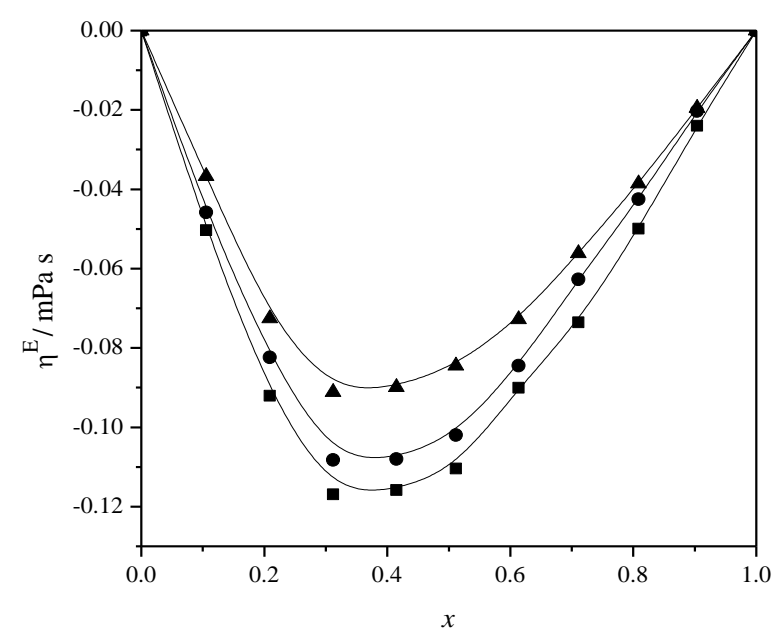

Figure 2. Excess viscosities as a function of concentration for $\operatorname{DEGDBE}(x)$ - ethanol $\boldsymbol{\|} 20{ }^{\circ} \mathrm{C} ; \bullet 25{ }^{\circ} \mathrm{C} ; \boldsymbol{\Delta} 30{ }^{\circ} \mathrm{C}$

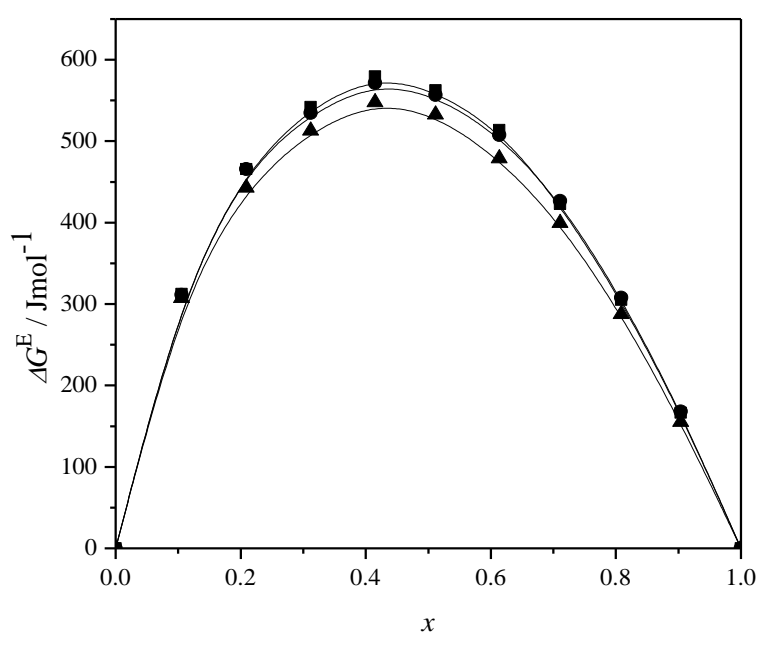

Figure 3. Excess Gibbs energies as a function of concentration for $\operatorname{DEGDBE}(x)$ - ethanol $\boldsymbol{\bullet} 20{ }^{\circ} \mathrm{C} ; \bullet 25{ }^{\circ} \mathrm{C} ; \boldsymbol{\Delta} 30{ }^{\circ} \mathrm{C}$

The excess functions of the binary solutions were matched with concentration using two equations:

a) The Redlich-Kister [19] relation:

$$
Y^{E}=x_{i} x_{j} \sum_{k=0}^{3} A_{k}\left(2 x_{i}-1\right)^{k}
$$

b)The Hwang expression [20]:

$$
Y^{E}=x_{i} x_{j}\left(A_{o}+A_{1} x_{i}^{3}+A_{2} x_{j}^{3}\right)
$$

where $Y^{\mathrm{E}}$ is any of the properties: $V^{\mathrm{E}}, \eta^{\mathrm{E}}$ and $\Delta G^{\mathrm{E}}, x_{i}, x_{j}$ represent the mole fractions of the compounds $i$ and $j$, respectively, and $A_{0}, A_{1}, A_{3}$ and $A_{\mathrm{k}}$ are the coefficients of the equations.

Tables 4-6 contain the values of the coefficients and of the standard deviation and show that the Redlich-Kister equation correlate better these excess functions. 
Table 4. Coefficients $A_{\mathrm{k}}$ and standard deviations, $\sigma$, for excess molar volume

\begin{tabular}{|c|c|c|c|}
\hline \multirow[b]{2}{*}{$A_{i}$ and $\sigma\left(\mathrm{cm}^{3} / \mathrm{mol}\right)$} & \multicolumn{3}{|c|}{$t /{ }^{0} \mathrm{C}$} \\
\hline & 20 & 25 & 30 \\
\hline \multicolumn{4}{|c|}{ Redlich-Kister equation } \\
\hline$A_{0}$ & -1.6513 & -1.7203 & -1.8559 \\
\hline$A_{1}$ & 0.4873 & 0.6045 & 0.6480 \\
\hline$A_{2}$ & $-0,3920$ & -0.6735 & -0.8262 \\
\hline$A_{3}$ & -1.0657 & -1.1542 & -1.1509 \\
\hline$\sigma$ & 0.0050 & 0.0072 & 0.0068 \\
\hline \multicolumn{4}{|c|}{ Hwang equation } \\
\hline$A_{0}$ & -1.5141 & -1.4886 & -1.5733 \\
\hline$A_{1}$ & -0.3949 & -0.6676 & -0.8180 \\
\hline$A_{2}$ & -0.6880 & -1.1688 & -1.4259 \\
\hline$\sigma$ & 0.0172 & 0.0195 & 0.0195 \\
\hline
\end{tabular}

Table 5. Coefficients $A_{\mathrm{k}}$ and standard deviations, $\sigma$, for excess viscosities

\begin{tabular}{|c|c|c|c|}
\hline \multirow[b]{2}{*}{$A_{i}$ and $\sigma(\mathrm{mPa} \cdot \mathrm{s})$} & \multicolumn{3}{|c|}{$t /{ }^{0} \mathrm{C}$} \\
\hline & 20 & 25 & 30 \\
\hline \multicolumn{4}{|c|}{ Redlich-Kister equation } \\
\hline$A_{0}$ & -0.4466 & -0.4143 & -0.3486 \\
\hline$A_{1}$ & 0.2558 & 0.2540 & 0.2042 \\
\hline$A_{2}$ & 0.0293 & 0.0741 & 0.0309 \\
\hline$A_{3}$ & -0.1591 & -0.1634 & -0.1500 \\
\hline$\sigma$ & 0.0024 & 0.0016 & 0.0021 \\
\hline \multicolumn{4}{|c|}{ Hwang equation } \\
\hline$A_{0}$ & -0.4551 & -0.4377 & -0.3577 \\
\hline$A_{1}$ & 0.2764 & 0.3321 & 0.2208 \\
\hline$A_{2}$ & -0.2055 & -0.1419 & -0.1449 \\
\hline$\sigma$ & 0.0040 & 0.0037 & 0.0035 \\
\hline
\end{tabular}

Table 6. Coefficients $A_{\mathrm{k}}$ and standard deviations, $\sigma$, for excess gibbs energy

\begin{tabular}{|c|c|c|c|}
\hline \multirow{2}{*}{$A_{i}$ and $\sigma(\mathrm{J} / \mathrm{mol})$} & \multicolumn{3}{|c|}{$t /{ }^{\circ} \mathrm{C}$} \\
\cline { 2 - 4 } & 20 & 25 & 30 \\
\hline \multicolumn{3}{|c|}{ Redlich-Kister equation } \\
\hline$A_{0}$ & 2257.53 & 2230.66 & 2124.32 \\
$A_{1}$ & -524.06 & -478.55 & -494.55 \\
$A_{2}$ & 487.09 & 562.87 & 534.60 \\
$A_{3}$ & -562.29 & -616.54 & -653.71 \\
$\sigma$ & 5.06 & 4.06 & 6.38 \\
\hline \multicolumn{4}{|c|}{ Hwang equation } \\
\hline$A_{0}$ & $2097.20 \quad-2045.44$ & -1948.70 \\
$A_{1}$ & -213.87 & -81.62 & 1565.23 \\
$\sigma$ & 1501.25 & 1569.02 & 8.89 \\
\hline
\end{tabular}

The molar excess volume values were used to test two theories: Flory [21-24] and Prigogine-FloryPatterson (PFP) [25,26].

The PFP theory includes three contributions: an interactional contribution $\left(V_{\mathrm{int}}^{\mathrm{E}}\right)$, the free volume contribution $\left(V_{\mathrm{FV}}^{\mathrm{E}}\right)$, and the internal pressure contribution $\left(V_{p^{*}}^{\mathrm{E}}\right)$.

The expression of the excess molar volume calculated with the Flory theory is:

$$
V^{E}=\frac{\left(x_{1} V_{1}^{*}+x_{2} V_{2}^{*}\right)\left(\varphi_{1} \tilde{v}_{1}+\varphi_{2} \tilde{v}_{2}\right)^{7 / 3}\left(\tilde{T}-\tilde{T}^{0}\right)}{(4 / 3)-\left(\varphi_{1} \tilde{v}_{1}+\varphi_{2} \tilde{v}_{2}\right)^{1 / 3}}
$$

The Prigogine Flory Patterson equation is:

$$
\frac{V^{E}}{x_{1} V_{1}^{*}+x_{2} V_{2}^{*}}=\frac{\left(\tilde{v}^{1 / 3}-1\right) \tilde{v}^{2 / 3} \psi_{1} \theta_{2} \chi_{12}}{\left((4 / 3) \tilde{v}^{-1 / 3}-1\right) p_{1}^{*}}-\frac{\left[\left(\tilde{v}_{1}-\tilde{v}_{2}\right)^{2}\left((14 / 9) \tilde{v}^{-1 / 3}-1\right) \psi_{1} \psi_{2}\right]}{\left[\left((4 / 3) \tilde{v}^{-1 / 3}-1\right) \tilde{v}\right]}+\frac{\left(\tilde{v}_{1}-\tilde{v}_{2}\right)\left(p_{1}^{*}+p_{2}^{*}\right) \psi_{1} \psi_{2}}{\psi_{1} p_{2}^{*}+\psi_{2} p_{1}^{*}}
$$


The coefficient of thermal expansion, $\alpha$, was calculated with relation [27]:

$$
\alpha=(1 / V)(\partial V / \partial T)_{p}
$$

The parameters in the equations 10 and 11 for the pure compounds and for the solution are reported in tables 7 and 8 .

The value of the interaction parameter $\chi_{12}$, was obtained from the experimental value of the excess molar volume for the equimolar solution [28].

Table 9 contains the results of $V^{\mathrm{E}}$ obtained by utilizations of equations 10 and 11 for $25{ }^{0} \mathrm{C}$. The values calculated were compared with the experimental ones by calculation the percentage absolute average deviation (ADD) with the relation:

$$
A D D \%=\frac{1}{n} \sum_{i=1}^{n} \frac{\left|Y_{\text {exp }}-Y_{\text {calc }}\right|}{Y_{\text {exp }}} .100
$$

where $n$ represent the number of experimental values and $Y$ is $V^{\mathrm{E}}$.

Table 7. Parameters of the pure components at $25^{\circ} \mathrm{c}$

\begin{tabular}{|c|c|c|c|c|c|c|c|c|}
\hline Component & $\begin{array}{c}10^{3 \cdot} \alpha, \\
\left(\mathrm{K}^{-1}\right)\end{array}$ & $\begin{array}{c}\mathrm{k}_{\mathrm{T}}, \\
\left(10^{4} \mathrm{MPa}^{-1}\right)\end{array}$ & $\tilde{v}$ & $\begin{array}{c}\mathrm{V}^{*}, \\
\left(\mathrm{~cm}^{3} / \mathrm{mol}\right)\end{array}$ & $\begin{array}{c}\mathrm{p}^{*}, \\
\left(\mathrm{~J}^{\prime} \mathrm{cm}^{3}\right)\end{array}$ & $\begin{array}{c}\mathrm{T}^{*}, \\
(\mathrm{~K})\end{array}$ & $\tilde{T}$ & $\mathrm{c}_{\mathrm{i}}$ \\
\hline DEGDBE & 1.037 & $8.29[4]$ & 1.2552 & 198.3169 & 587.6445 & 5128.371 & 0.0581 & 2.7333 \\
\hline ethanol & 1.005 & $11.53[29]$ & 1.2487 & 46.9562 & 405.2361 & 5216.785 & 0.0571 & 0.4387 \\
\hline
\end{tabular}

Table 8.Parameters of the liquid mixture for flory and prigogine-flory-patterson theories

\begin{tabular}{|c|c|c|c|c|c|c|}
\hline Solution & $\varphi_{2}$ & $\theta_{2}$ & $\tilde{v}$ & $\tilde{T}$ & $\chi_{12},\left(\mathrm{~J} / \mathrm{cm}^{3}\right)$ & $\psi_{1}$ \\
\hline DEGDBE(1)-ethanol(2) & 0.1914 & 0.1278 & 1.2505 & 0.0574 & -53.9431 & 0.8596 \\
\hline
\end{tabular}

Table 9. Experimental and calculated excess volume at 0.5 mole fraction and calculated values of the three contributions to $V^{\mathrm{E}}$

\begin{tabular}{|c|c|c|c|c|c|c|}
\hline Solution & $\begin{array}{c}V_{\text {exp }}^{E}, \\
\left(\mathrm{~cm}^{3} / \mathrm{mol}\right)\end{array}$ & $\begin{array}{c}V_{\text {cal PFP }}^{E}, \\
\left(\mathrm{~cm}^{3} / \mathrm{mol}\right)\end{array}$ & $\begin{array}{c}V_{i n t}^{E}, \\
\left(\mathrm{~cm}^{3} / \mathrm{mol}\right)\end{array}$ & $\begin{array}{c}V_{F V}^{E} \\
\left(\mathrm{~cm}^{3} / \mathrm{mol}\right)\end{array}$ & $\begin{array}{c}V_{p^{*}}^{E} \\
\left(\mathrm{~cm}^{3} / \mathrm{mol}\right)\end{array}$ & $\begin{array}{c}V_{\text {cal FLORY }}^{E} \\
\left(\mathrm{~cm}^{3} / \mathrm{mol}\right)\end{array}$ \\
\hline DEGDBE -ethanol & -0.43007 & -0.4274 & -0.4673 & 0.0009 & 0.0408 & -0.4323 \\
\hline
\end{tabular}

The obtained results show that the ADD value using Flory theory for prediction of excess molar volume is less than $0.5 \%$ and for Prigogine-Flory-Patterson theory the value is less than $0.6 \%$. These values indicate that the tested theories are capable to correlate the experimental value. An analysis of each of the three contributions to excess molar volume shows that the free volume contribution and the internal pressure contribution are positive, while the interactional contribution is negative.

\section{Conclusions}

The densities and viscosities of binary mixtures of DEGDBE - ethanol were determined experimentally at 20,25 and $30^{\circ} \mathrm{C}$. From these results, the excess values properties have been determined and correlated with the Redlich-Kister and Hwang equations. Negative values were observed for excess molar volume and excess viscosities while, positive deviations were obtained for excess Gibbs energies. The excess molar volume value of the equimolar solution was used to test the Flory and Prigogine-Flory-Patterson theories. ADD values show the validity of these theories for the system studied in this work.

\section{References}

1. DHONDGE, S. S., PANDHURnEKAR, C. P., PARWATE, D. V., J. Chem. Thermodynamics, 41, no. 5, 2009, p. 577

2. SIMA, S., CRISCIU, A., FEROIU, V., SECUIANU, C., Rev. Chim., 65, no. (2), 2014, 202

3. CIOCIRLAN, O., IULIAN, O., Rev. Chim., 59, (1), 2008, 45 
4. PAL, A., KUMAR, A., J. Chem. Sci., 116, no. 1, 2004, p. 39

5. HENNI, A., TONTIWACHWUTHIKUL, P., CHAKMA, A., J. Chem. Eng. Data, 51, no. 1, 2006, p. 64

6. ESTEVE, X., CONESA, A., CORONAS, A., J. Chem. Eng. Data, 48, no. 2, 2003, p. 392

7. ZHANG, N., ZHANG, J., ZHANG, Y., BAI, J., HUO, T., WEI, X., Fluid Phase Equilibria, 313, no. 1,2012 , p. 7

8. WEISSBERGER, A., Physical methods of Organic Chemistry Interscience Publishers Inc, (New York), 1959

9. PAL, A., BHARDWAJ, R.K., DASS, G., International Journal of Thermophysics, 22, no. 3, 2001, p. 769

10. CARMONA, F.J., ARROYO, F.J., GARCIA DE LA FUENTE, G.I., GONZALEZ, J.A., COBOS, J.C., Can. J. Chem., 77, 1997, p.1608

11. VUKSANOVIC, J.M., RADOVIC, I.R., SERBANOVIC, S.P., KIJEVCANIN, M.L.J., J. Serb. Chem. Serb., 80, no. 7, 2015, p.933

12. HOU, C., JIANG, Z., REN, B., J. Chem. Eng. Data, 55, no. 11, 2010, p. 4943

13. JACQUEMIN, J., HUSSON, P., PADUA, A.A.H \& MAJER, V., Green Chem., 8, no. 2, 2006, p. 162

14. MARQUARDT, D.W., J. Soc. Indust. Appl. Math., 11, no. 2, 1963, p. 431

15. LI, X-X., HU, Y.J., LIU, G., J. Chem. Eng. Data, 55, no. 2, 2010, p. 1045

16. MAHAJAN, A.R., MIRGANE, S.R., Journal of Thermodynamics, 2013, doi:10.1155/2013/ $\underline{571918}$

17. MEYER, R., MEYER, M., METZER, J., PENELOUX, A., J. Chim. Phys, 68, 1971, p. 406

18. REED, T.M., TAYLER, T.E., J. Phys. Chem., 63, no. 1, 1959, p. 58

19. REDLICH, O., KISTER, A.T., Ind. Eng. Chem., 40, no. 2, 1948, p. 341

20. HWANG, C.A., HOLSTE, J.C., HALL, K.R., MANSOORI, G.A., Fluid Phase Equilib., 62, no. 3, 1991, p. 173

21. FLORY, P.J., J. Am. Chem. Soc.,87, no. 9, 1965,p. 1833

22. ABE, A., FLORY, P.J.,J. Am. Chem. Soc.,87, no. 9, 1965, p. 1838

23. FLORY, P.J., ORWOLL, R.A., VRIJ, A.,J. Am. Chem. Soc.,86, no. 17, 1964, p. 3507

24. ORWOLL, R.A., FLORY, P.J.,J. Am. Chem. Soc.,89, no. 26, 1967,p. 6814

25. VAN, H.T., PATTERSON, D.,J. Solution Chem.,11, no. 11, 1982, p.793

26. PRIGOGINE, I., TRAPPENIERS, N., MATHOT, V., J. Chem. Phys.,21, no. 3, 1953,p.559

27. NIKAM, P.S., JAGDALE, B.S., SAWANT, A.B., HASAN, M.,J. Chem. Eng. Data45, no. 2, 2000, p. 214

28. BUDEANU, M. M., DUMITRESCU, V., J. Serb. Chem. Soc., 82, no. 7-8, 2017, p. 891

29. FUNKE, H., WETZEL, M., HEINTZ, A., Pure Appl. Chem., 61, no. 8, 1989, p.1429.

Manuscript received: 26.11 .2019 